\title{
Assessment of socio-behavioural correlates and risk perceptions regarding anthrax disease in tribal communities of Odisha, Eastern India
}

\author{
Matrujyoti Pattnaik ${ }^{1 \dagger}$, Jaya Singh Kshatri ${ }^{1 \dagger}$, Hari Ram Choudhary ${ }^{1 \dagger}$, Debaprasad Parai ${ }^{1 \dagger}$, Jyoti Shandilya ${ }^{1 \dagger}$, \\ Asit Mansingh ${ }^{1}$, Arun Kumar Padhi ${ }^{2}$, Sanghamitra Pati ${ }^{*}$ and Debdutta Bhattacharya ${ }^{1 *}$
}

\begin{abstract}
Background: This study is a baseline survey to assess the knowledge, attitude and practices with regards to the anthrax disease among the communities before demonstrating a One Health approach for elimination of human anthrax in an endemic district of Odisha. A total of 2670 respondents from 112 villages of 14 blocks were interviewed for the study using a structured questionnaire by multi-stage sampling method. Descriptive statistics were reported and logistic regression was performed to estimate the relationship between the variables and knowledge of anthrax.

Result: Out of 2670 participants in the study, $76.25 \%$ were male and about half were illiterate. Most of the respondents (54.19\%) were involved in agriculture as an occupation. $71 \%$ of the respondents had livestock in their houses and farming was the main purpose for keeping the livestock. Only one-fifth of the respondents (20.26\%) knew about anthrax and a majority of them have come across the disease during community outbreaks. Almost $25.9 \%$ of livestock owners had knowledge about vaccination against anthrax disease although $83.4 \%$ of the livestock owners disposed the animal carcass by burial method.
\end{abstract}

Conclusion: The study findings indicated that the community members had poor knowledge of cause, symptoms, transmission and prevention of anthrax disease which may be improved by a One Health approach.

Keywords: Anthrax, Knowledge-attitude-practices, Koraput, Endemic region, One Health

\section{Introduction}

Anthrax is a globally neglected zoonotic disease caused by Bacillus anthracis and is widely found in cattle, goats, sheep and deer $[1,2]$. Humans often got the disease when they come in close contact with an infected animal. The risk of an anthrax outbreak in the endemic areas is increased due to the exposure of inactive Bacillus

*Correspondence: drsanghamitra12@gmail.com; drdebduttab.rmrc-od@gov. in

${ }^{\dagger}$ Matrujyoti Pattnaik, Jaya Singh Kshatri, Hari Ram Choudhary, Debaprasad Parai and Jyoti Shandilya have contributed equally

${ }^{1}$ Department of Microbiology, ICMR-Regional Medical Research Centre (Department of Health Research, Ministry of Health \& Family Welfare, Government of India), Chandrasekharpur, Bhubaneswar 751023, India Full list of author information is available at the end of the article anthracis spores from the soil [3, 4]. These spores are then swallowed by the herbivores during grazing which are then germinated inside the body and manifests various disease symptoms [5].

Anthrax has three clinical forms in humans based on the route of infection namely cutaneous (skin), gastrointestinal (ingestion) and pulmonary anthrax [6]. It is a disease more prevalent among animal handlers who get infected from contamination during the production, processing and handling of animal products and also among people who ingest/consume infected meat $[7,8]$. Lack of awareness among livestock owners regarding anthrax is one of the most important factors leading to the disease 
outbreaks and becomes a big hurdle in controlling the disease [9].

In India, anthrax cases have been reported from different states like Odisha, Andhra Pradesh, Jammu \& Kashmir, Tamil Nadu and Karnataka. In the last 15 years, 14 out of 30 districts have witnessed repeated outbreaks of anthrax affecting at least 1208 people, mostly cutaneous anthrax of which 436 had died in Odisha $[10,11]$. The anthrax outbreaks become an endemic in few parts of this state and the most frequently affected districts are Koraput, Rayagada, Malkangiri, Sundargarh, and Kandhamal of which Koraput district tops the list with more than 300 human cases and more than 10 deaths with confirmed anthrax infection during the last 6 years $[11,12]$.

The following study is a baseline study which was conducted as a part of a One Health approach demonstration to map the current knowledge, attitude and practices among the communities residing in Koraput district of Odisha and to enlist the risky practices that can be a potential threat to catch the disease.

\section{Materials and methods Study design}

The study was a cross-sectional survey conducted as a baseline before using the intervention of the One Health approach for the elimination of human anthrax cases in the district. This study was conducted from February 2020 to October 2020. All methods were carried out in accordance with relevant guidelines and regulations.

\section{Study settings}

The study was undertaken in the Koraput district, which is situated in south Odisha spreading out over 8807 sq. $\mathrm{km}$ with 14 blocks and 2028 revenue villages. It lies between $18.8561^{\circ} \mathrm{N}$ latitude and $82.7347^{\circ} \mathrm{E}$ longitude.

\section{Sample size}

The sample size was calculated by using the formula stated in Bhattacharya et al. [13]. Assuming the knowledge of anthrax in the community as $5 \%$ with a design effect of 1.3 and confidence interval of $95 \%$, relative precision of $20 \%$ and non-response rate of $10 \%$ was calculated to a total of 2608 which was rounded off to 2640 .

\section{Sampling method}

A multistage simple random sampling method was adopted for selecting the study participants from all the 14 blocks in the district. Block is a district sub-division and Gram Panchayat is the basic village governing body in Indian villages consisting of several villages. A list of fourteen blocks with total Gram panchayats and their total villages were made according to census 2011 for randomisation. The list of selected Gram panchayats and villages are provided as Additional file 1 (Annexure 1 and 2).

We have selected two Gram Panchayats from each administratively divided block and further four villages from each Gram Panchayat were selected based on simple random sampling using the random number generation method. If the number of villages in a Gram Panchayat was less than four, then another Gram Panchayat was selected randomly from the same block. In this way, 112 villages were selected for data collection in the district. In each selected village, households were selected systematically and only one adult individual was enrolled from each selected house. If there were two or more adults in one house, then simple random sampling was followed to select an individual for the study. The flow diagram for sampling is provided in (Fig. 1).

\section{Data collection}

A questionnaire was developed with 85 -items based on the contents described in the Bhattacharya et al [13]. The structured questionnaire primarily consisted of semiopen questions and was arranged into domains namely socio-demographic characteristics (age, sex, education level, occupation, number of people in the household,

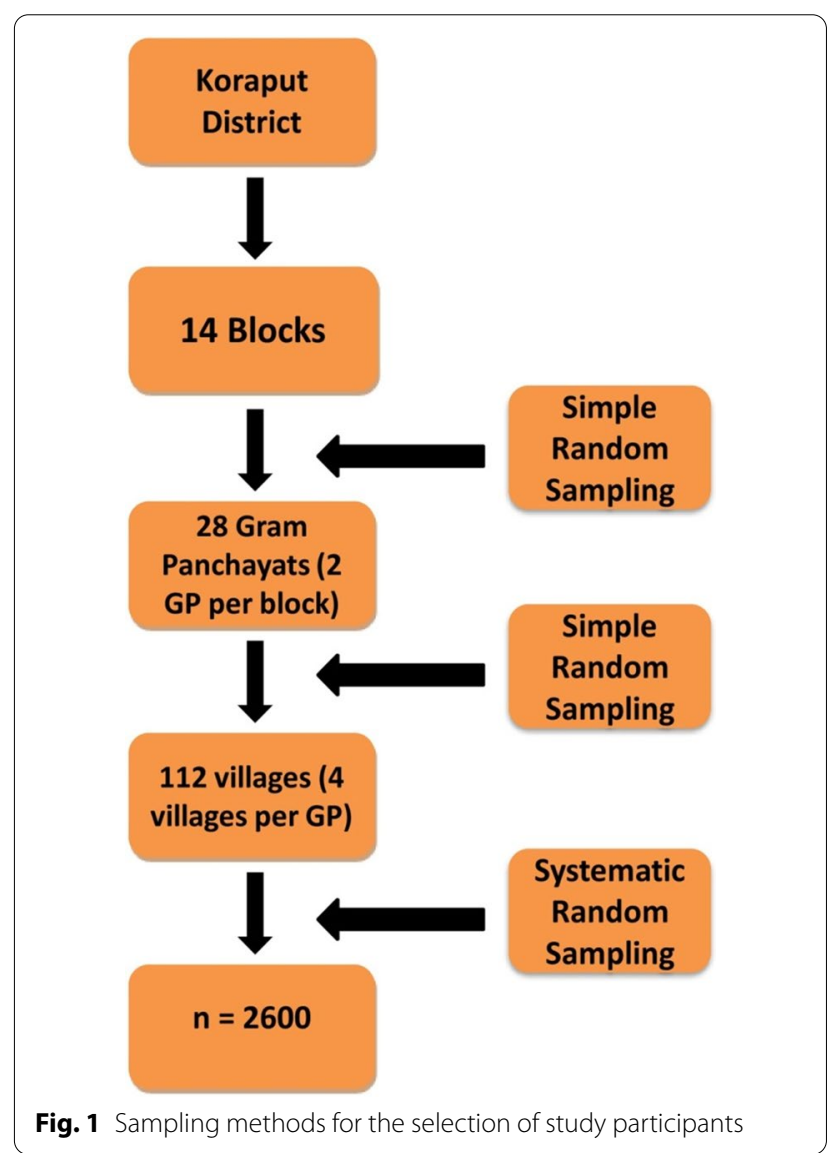


animal ownership status), information on domestic animal (type of livestock, grazing habits, years of experience in handling livestock), dead-animal handling, food habits (consumption of meat and its sources) and knowledge assessment \& awareness of the respondent about anthrax disease (signs or symptoms, transmission, precaution and prevention). The questionnaire was uploaded in Open Data Kit and data were collected using electronic devices. The field staff were provided with hands-on training for collecting the data through the tablet. The collected data were downloaded at regular intervals and data cleaning and monitoring were carried out by the data handler.

\section{Data analysis}

Statistical Package for Social Sciences (SPSS) version 21 was used for data analysis. The frequency distribution and percentages of the variables were calculated. The bivariate and multivariate logistic regression determined whether variables such as age, gender, educational level, occupation, presence or absence of livestock and meat consumption influenced the knowledge of anthrax at a significance level of 0.05 . Heat map regarding knowledge of anthrax disease was done using QGIS (ver. 3.10).

\section{Results}

A total of 2670 individuals were surveyed from 112 villages across 14 blocks of the district. Socio-demographic characteristics of the study population are provided in Table 1. More than 3/4th (76.25\%) of the studied population were male with a mean age of males being $40.4 \pm 14.4$ years and the mean age of females were recorded as $38.1 \pm 13.8$ years. Most of the study population were in the 18-29 age group (26.75\%). The study participants mainly belonged to the Hindu religion (86.78\%) and were tribal (62.43\%). Respondents were classified into illiterate who received no formal education and literate who have completed atleast primary, secondary or tertiary level of education. More than $50 \%$ of the respondents were illiterate and a majority of the population $(54.19 \%)$ were found to be engaged in agricultural practices.

Information about livestock handling is provided in Table 2. Of all the households visited, $71.42 \%$ of the households were having livestock. Most of the households were having cattle/buffalos (96.06\%), then goat (24.49\%) and sheep (18.56\%) respectively. The main purpose for keeping the livestock was for cultivating the agricultural field (82.12\%) followed by dairy farming $(24.59 \%)$ and selling meat (17.93\%). Forest (61.98\%) was the most preferred place for grazing of animals along with grass fields (18.51\%) and agricultural lands (17.99\%).

Knowledge of anthrax refers to the people who could tell the signs and/or symptoms and/or transmission of anthrax in either humans or animals. Categorization of
Table 1 Socio-demographic information of the study participants in Koraput district

\begin{tabular}{|c|c|c|}
\hline Variables & Frequency & Proportion (\%) \\
\hline \multicolumn{3}{|l|}{ Gender } \\
\hline Male & 2036 & 76.25 \\
\hline Female & 634 & 23.75 \\
\hline \multicolumn{3}{|l|}{ Age-groups } \\
\hline $18-29$ & 714 & 26.75 \\
\hline $30-39$ & 633 & 23.7 \\
\hline $40-49$ & 542 & 20.3 \\
\hline $50-59$ & 397 & 14.87 \\
\hline 60 and above & 384 & 14.38 \\
\hline \multicolumn{3}{|l|}{ Category } \\
\hline General & 259 & 9.7 \\
\hline Other backward caste & 330 & 12.36 \\
\hline Schedule caste & 414 & 15.51 \\
\hline Schedule tribe & 1667 & 62.43 \\
\hline \multicolumn{3}{|l|}{ Education } \\
\hline Illiterate & 1432 & 53.63 \\
\hline Literate & 1238 & 46.37 \\
\hline \multicolumn{3}{|l|}{ Annual income (in Rs) } \\
\hline Less than 10,000 & 496 & 18.58 \\
\hline $10,000-50,000$ & 1598 & 59.85 \\
\hline More than 50,000 & 576 & 21.57 \\
\hline \multicolumn{3}{|l|}{ Household size } \\
\hline $1-3$ & 533 & 19.96 \\
\hline $4-6$ & 1546 & 57.91 \\
\hline 7 and more & 591 & 22.13 \\
\hline \multicolumn{3}{|l|}{ Occupation } \\
\hline Unemployed & 128 & 4.79 \\
\hline Government service & 61 & 2.28 \\
\hline Private service & 87 & 3.27 \\
\hline Housewife & 148 & 5.54 \\
\hline Agriculture & 1447 & 54.19 \\
\hline Business & 173 & 6.48 \\
\hline Daily labour & 626 & 23.45 \\
\hline
\end{tabular}

the study population according to the knowledge, attitude and practices regarding anthrax is shown in Table 3. Around $20.26 \%$ of people were aware of anthrax disease in animals and humans. Most of the respondents (43.3\%) knew about anthrax from the community, 19.2\% from the doctors, $13.7 \%$ from the veterinary department, $14.6 \%$ from media such as newspapers, internet, television, etc. and $9.2 \%$ from healthcare workers like Accredited Social Health Activist (ASHA), Auxiliary Nurse-Midwife (ANM), Anganwadi Workers (AWW), Primary Health Centre (PHC) doctors etc. (Fig. 2). A heat map for blocks regarding the distribution of participants who knew about anthrax is given in Fig. 3. One-fourth of 
Table 2 Information about livestock and animal handling

\begin{tabular}{|c|c|c|}
\hline Question & Frequency & Proportion (\%) \\
\hline \multicolumn{3}{|c|}{ Respondents having livestock $(n=2670)$} \\
\hline Yes & 1907 & 71.42 \\
\hline No & 763 & 28.58 \\
\hline \multicolumn{3}{|c|}{ Person's dealing with the livestock $(n=1907)$} \\
\hline Myself & 1269 & 66.54 \\
\hline Wife/Husband & 218 & 11.43 \\
\hline Parents & 222 & 11.65 \\
\hline Son & 104 & 5.45 \\
\hline Other relatives & 94 & 4.93 \\
\hline \multicolumn{3}{|c|}{ Respondents having which livestock ${ }^{\#}(n=1907)$} \\
\hline Cattle/Buffalo & 1832 & 96.06 \\
\hline Goat & 467 & 24.49 \\
\hline Pig & 30 & 1.57 \\
\hline Sheep & 354 & 18.56 \\
\hline \multicolumn{3}{|c|}{ Purpose of keeping livestock animals $(n=1907)$} \\
\hline Leather industry & 2 & 0.1 \\
\hline Skinning & 6 & 0.31 \\
\hline Dairy & 469 & 24.59 \\
\hline Farming & 1566 & 82.12 \\
\hline Selling meat & 342 & 17.93 \\
\hline \multicolumn{3}{|c|}{ Respondent's preferred place for grazing $(n=1907)$} \\
\hline Forest & 1182 & 61.98 \\
\hline Agricultural land & 343 & 17.99 \\
\hline Grass field & 353 & 18.51 \\
\hline Buy commercial fodder & 29 & 1.52 \\
\hline \multicolumn{3}{|c|}{ Respondent's having how many years of experience in handling livestock animals $(n=1907)$} \\
\hline Less than 1 year & 140 & 7.34 \\
\hline $1-5$ years & 200 & 10.49 \\
\hline $5-10$ years & 284 & 14.89 \\
\hline More than 10 years & 1283 & 67.28 \\
\hline
\end{tabular}

\# Multiple choices were noted

the population handling livestock (25.9\%) was aware of the anthrax vaccination of animals which is a preventive method for controlling anthrax disease among livestock animals. More than $70 \%$ of livestock owners inform relevant authorities on suspected anthrax cases in animals, whereas $23 \%$ of the people do not report it. About the risk practices and intended behaviour of persons towards anthrax, $14.75 \%$ of the study population was involved in the consumption of beef and $25.03 \%$ consume animal blood in their diet. Approximately 4.2\% of the livestock owners consume the dead animal's meat. Among livestock owners, $2.8 \%$ distribute the dead animals among villagers and $2.6 \%$ sell the carcass. Around $83 \%$ of the livestock owners were involved in burial of dead animals where they dig a land upto 5 feet and bury the dead animal in the presence of livestock inspector or veterinary doctor.
The odds ratio of both unadjusted and adjusted with their 95\% confidence intervals (CIs) were used to assess the association as in Table 4. People with the age group 30-39 years had 1.4 times higher odds of possessing knowledge about anthrax compared to the people of the reference age group. Males were more likely to possess the knowledge of anthrax than females which might be due to the livestock handling predominantly done by them. Compared to the participants who received no formal education, those who had received formal education were two times more likely to possess the knowledge of anthrax. Participants who had more than 10 years of experience in handling livestock were 1.4 times more probable of possessing the knowledge of anthrax than others who had less than 10 years of experience. 
Table 3 Participant's knowledge, attitude and practices towards anthrax disease in Koraput

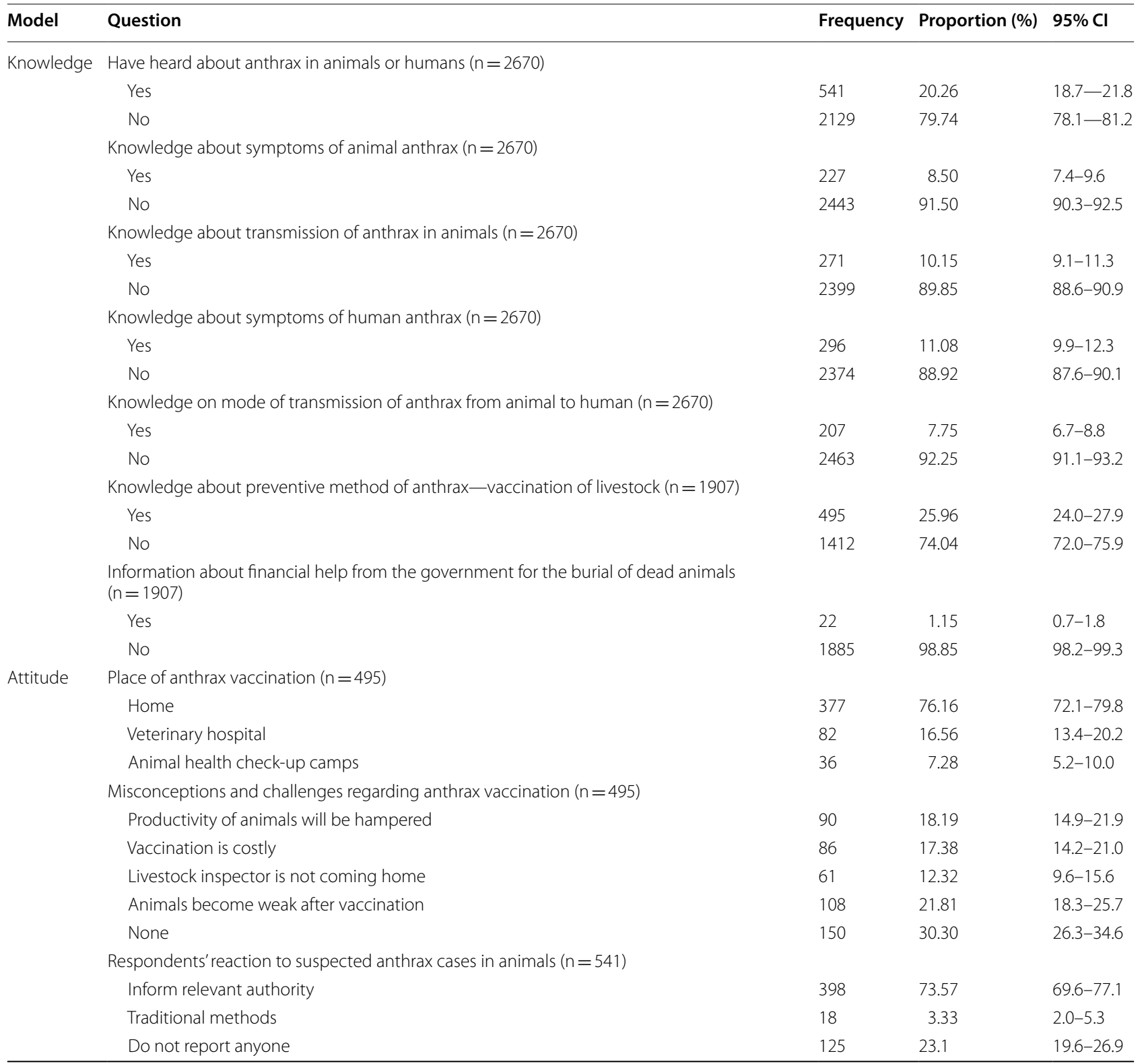


Table 3 (continued)

\begin{tabular}{|c|c|c|c|c|}
\hline Model & Question & Frequency & Proportion (\%) & $95 \% \mathrm{Cl}$ \\
\hline \multirow{28}{*}{ Practices } & \multicolumn{4}{|l|}{ Vaccinated their livestock animals against anthrax $(n=1907)$} \\
\hline & Yes & 406 & 21.29 & $19.5-23.2$ \\
\hline & No & 1501 & 78.71 & $76.7-80.5$ \\
\hline & \multicolumn{4}{|l|}{ Period of conduction of anthrax vaccination of animals $(n=406)$} \\
\hline & Less than 6 months & 245 & 60.35 & $55.4-65.1$ \\
\hline & 6 months-1 year & 117 & 28.81 & $24.5-33.5$ \\
\hline & $1-2$ years & 23 & 5.67 & $3.7-8.5$ \\
\hline & More than 2 years & 21 & 5.17 & $3.3-7.9$ \\
\hline & \multicolumn{4}{|l|}{ Was the anthrax vaccination free of cost $(n=406)$} \\
\hline & Yes & 162 & 39.90 & $35.1-44.8$ \\
\hline & No & 244 & 60.10 & $55.1-64.8$ \\
\hline & \multicolumn{4}{|l|}{ Respondent's meat consuming habit $(n=2670)$} \\
\hline & Yes & 2393 & 89.63 & $88.3-90.7$ \\
\hline & No & 277 & 10.37 & $9.3-11.6$ \\
\hline & \multicolumn{4}{|l|}{ Type of meat the respondents consume ${ }^{\#}(n=2393)$} \\
\hline & Beef & 353 & 14.75 & $13.4-16.2$ \\
\hline & Pig & 135 & 5.64 & $4.7-6.6$ \\
\hline & Sheep & 2204 & 92.1 & 90.9-93.1 \\
\hline & Goat & 1810 & 75.64 & $73.8-77.3$ \\
\hline & \multicolumn{4}{|l|}{ Respondent's consuming animal blood in their diet $(n=2393)$} \\
\hline & Yes & 599 & 25.03 & $23.3-26.8$ \\
\hline & No & 1794 & 74.97 & $73.1-76.6$ \\
\hline & \multicolumn{4}{|c|}{ Respondents managing dead bodies of livestock animals $(n=1907)$} \\
\hline & Burial & 1591 & 83.43 & $81.6-85.1$ \\
\hline & Throw themaway & 129 & 6.77 & $5.7-8.0$ \\
\hline & Distribute among villagers & 55 & 2.88 & $2.2-3.7$ \\
\hline & Selling the carcass & 51 & 2.67 & $2.0-3.5$ \\
\hline & Consume the meat & 81 & 4.25 & $3.4-5.3$ \\
\hline
\end{tabular}

\# Multiple choices were noted

\section{Discussion}

The study provides preliminary baseline information regarding the knowledge, attitude and practices of anthrax among the people of Koraput district. In our study, socio-demographic characteristics from the community were significantly associated with the knowledge of anthrax. Many communities in the district have very low levels of understanding of human and animal anthrax disease, which leads them to the risk of anthrax exposure as well as underreporting of the cases to the health officials. There are some harmful practices which include eating livestock blood, eating dead animals' meat, distributing or selling carcasses to local people and even throwing carcasses anywhere in the field. Such occurrences may lead to environmental contamination by anthrax spores [14]. Once the spores are released into the environment, they can remain viable for a period of 90 years or more and can be a source of future outbreaks [15]. The attention of authorities towards anthrax is sought when outbreaks happen in the community, making people sick or dead after consuming infected or uninspected meat [16]. Almost $71 \%$ of the population owns livestock of which 




Fig. 2 Distribution of information regarding anthrax from the participants who knew about anthrax

96\% have cattle/buffalo, which indicates that the community is highly dependent on cattle for livelihood. This could be one of the major reasons for frequent outbreaks in cattle than any other livestock in Koraput [17]. Majority of livestock visit the forest for grazing which can be another factor of ingesting spores and a possible risk factor for anthrax disease outbreaks among animals. Several studies have hypothesized the seasonal variations or climate conditions for anthrax disease outbreaks, and there is strong evidence regarding their association [18-20].
Around $21.2 \%$ of livestock owners have vaccinated their animals against anthrax disease which shows a lack of anthrax vaccination knowledge and practice in the community. Veterinarians contribute a major role in building and implementing disease control programs in livestock. The annual vaccination of livestock against anthrax significantly lowers the odds of acquiring anthrax than those that were never vaccinated [21]. Non-livestock owners had less knowledge about anthrax disease than livestock owners, as it was expected that the disease occurs mainly in livestock animals but it was not significantly associated. The Government is providing financial assistance for the burial of dead animals to the livestock owners but more than $98 \%$ of the livestock owners are unaware of the incentive as per our study. Livestock owners had indigenous knowledge of various diseases affecting their livestock but awareness of anthrax disease, vaccination of animals against anthrax and the government incentive for burial of dead animals was lacking in most cases which must be done by the local governmental organizations or veterinary department. The education of livestock owners for the handling of anthrax suspect cases or dead livestock animals is very important by training them on the proper burial of animals and not to cut such carcasses or consume them. Anthrax is a neglected zoonotic disease that is often underreported from its actual prevalence

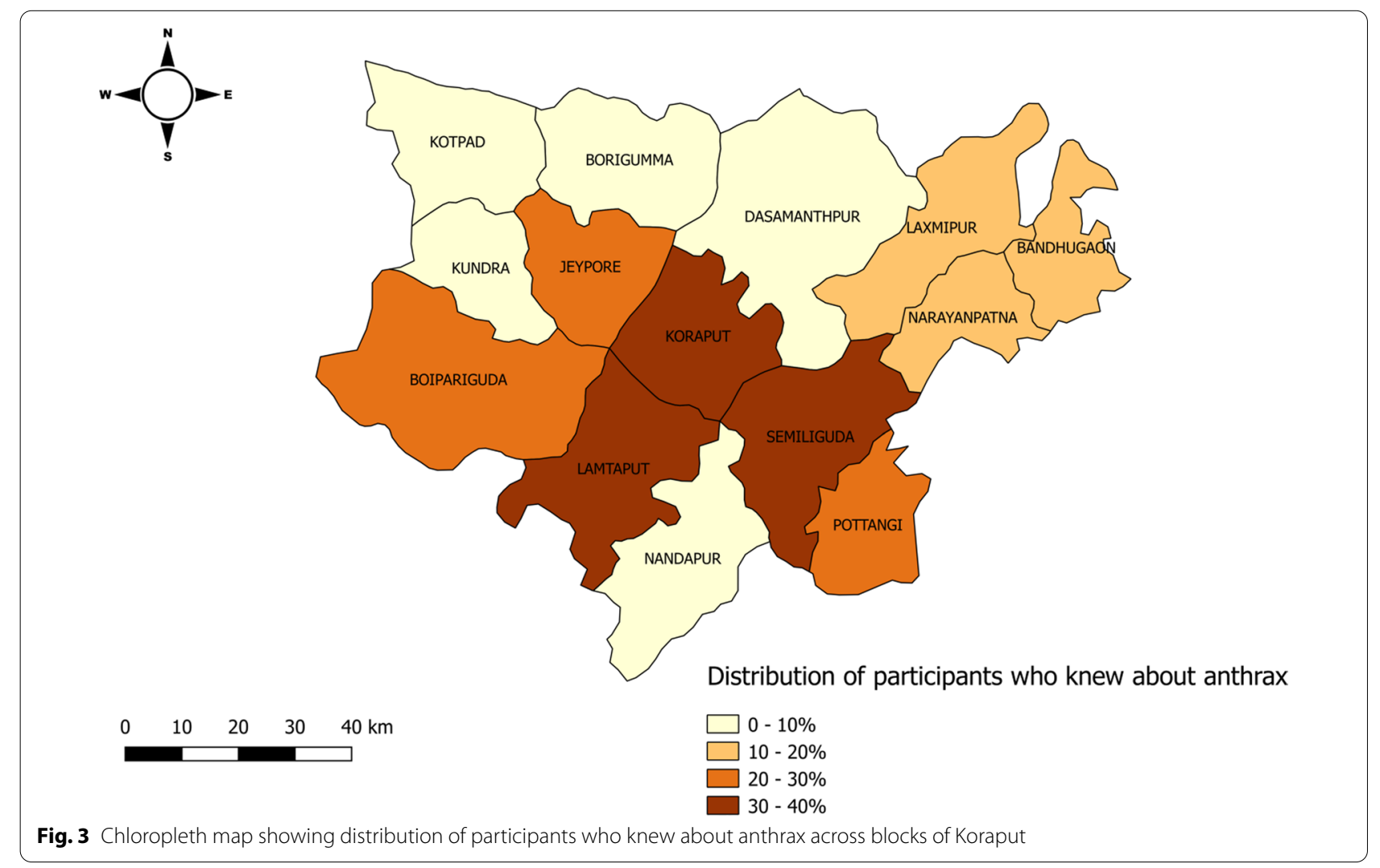


Table 4 Bivariate and multivariate logistic regression analysis output of factors associated with knowledge of anthrax

\begin{tabular}{|c|c|c|c|c|c|c|c|c|c|}
\hline Characteristic & Comparison & $\begin{array}{l}\text { Knowledge } \\
\text { of anthrax }\end{array}$ & Total & $\begin{array}{l}\text { Unadjusted } \\
\text { odds ratio }\end{array}$ & 95\% C.I. & $p$-value & $\begin{array}{l}\text { Adjusted } \\
\text { odds ratio }\end{array}$ & 95\% C.I. & p-value \\
\hline \multirow[t]{5}{*}{ Age } & $18-29$ & 138 & 714 & Reference & & & & & \\
\hline & $30-39$ & 162 & 633 & 1.43 & $1.11-1.85$ & $<0.01$ & 1.48 & $1.08-2.03$ & 0.02 \\
\hline & $40-49$ & 105 & 542 & 1 & $0.75-1.33$ & 0.98 & 0.96 & $0.69-1.42$ & 0.96 \\
\hline & $50-59$ & 73 & 397 & 0.94 & $0.68-1.28$ & 0.7 & 1.07 & $0.72-1.57$ & 0.73 \\
\hline & 60 \& above & 63 & 384 & 0.81 & $0.59-1.13$ & 0.23 & 0.98 & $0.65-1.49$ & 0.95 \\
\hline \multirow[t]{2}{*}{ Gender } & Female & 60 & 634 & Reference & & & & & \\
\hline & Male & 481 & 2036 & 2.95 & $2.22-3.93$ & $<0.01$ & 2.20 & $1.50-3.22$ & $<0.01$ \\
\hline \multirow[t]{2}{*}{ Education } & Illiterate & 191 & 1432 & Reference & & & & & \\
\hline & Literate & 350 & 1238 & 2.56 & $2.10-3.11$ & $<0.01$ & 2.17 & $1.68-2.79$ & $<0.01$ \\
\hline \multirow[t]{2}{*}{ Occupation } & Non-agriculture & 243 & 1260 & Reference & & & & & \\
\hline & Agriculture & 298 & 1410 & 1.12 & $0.92-1.35$ & 0.23 & 1.09 & $0.85-1.39$ & 0.47 \\
\hline \multirow[t]{2}{*}{ Livestock } & Absent & 138 & 763 & Reference & & & & & \\
\hline & Present & 403 & 1907 & 1.21 & $0.97-1.50$ & 0.07 & 1.17 & $0.93-1.47$ & 0.18 \\
\hline \multirow[t]{2}{*}{ Experience of handling livestock } & Less than 10 years & 103 & 624 & Reference & & & & & \\
\hline & More than 10 years & 300 & 1283 & 1.54 & $1.20-1.97$ & 0.01 & 1.49 & $1.14-1.94$ & $<0.01$ \\
\hline \multirow[t]{2}{*}{ Meat consumption } & No & 31 & 277 & Reference & & & & & \\
\hline & Yes & 510 & 2393 & 2.14 & $1.46-3.16$ & $<0.01$ & 1.79 & $1.13-2.82$ & 0.01 \\
\hline
\end{tabular}

[22]. Establishing a surveillance network for reporting anthrax cases in endemic districts can be beneficial in preventing outbreaks of the disease. The findings from the study could open the doors for future contributions, research efforts and also can be used to optimize prevention and control strategies, including vaccination of livestock and educational campaigns of livestock owners.

\section{Conclusion}

This study highlights substantial knowledge and practice gaps on anthrax in the community which indicates a need for improvement in these areas. Several risk practices were identified such as consumption, distribution and trading of dead animal meat which could be the potential factors in the transmission of anthrax from animal to human. A surveillance system for early case detection and proper education among the community regarding anthrax is essential for the timely detection, prevention and control of outbreaks. Immediate measures should be taken to maximize the coverage of anthrax vaccination among the livestock of the district. Active interdepartmental coordination by adopting the One Health approach in endemic regions is a potential method to address these gaps.

\section{Supplementary Information}

The online version contains supplementary material available at https://doi. org/10.1186/s12879-022-07035-9.

Additional file 1. Block-wise sample collection distribution.

\section{Acknowledgements}

The authors gratefully acknowledge all the participants for voluntarily participating in this study and for sharing valuable information and experiences. We are also thankful to our research team including Biren Kumar Padhi, Padma Mohan Pradhan, Subrat Kumar Sahoo and Annalisha Peter.

\section{Authors' contributions}

SP and DB conceptualized and designed the study. The field activities and data collection were executed by MP, JSK, HRC, DP, JS, AM and AKP. MP, SP and DB wrote the initial draft of the manuscript and reviewed by JSK, HRC and DP. Analyses were done by MP, JSK, HRC, DP and JS. All authors read and approved the final manuscript.

\section{Funding}

This research was funded by the Indian Council of Medical Research, New Delhi (Grant Number: ZON/33/1/2018-ECD-II). The funding body was not involved in the design of the study and collection, analysis, and interpretation of data, or in writing the manuscript.

\section{Availability of data and materials}

Raw data will be available on request to the corresponding author.

\section{Declarations}

\section{Ethics approval and consent to participate}

Ethical clearance was obtained from the Institutional Human Ethics Committee of ICMR-Regional Medical Research Centre (RMRC), Bhubaneswar [ECH/911/Inst/OR/2017]. Each participant was explained about the aims and objectives of the study and provided with the participant information sheet for reference. Written informed consent was taken from each literate participant and the same was obtained from legally authorized representatives/ tribe's head for illiterate participant before participation in the study. There was no child participant in this study. The study was conducted following the relevant ethical guidelines of Indian Council of Medical Research, New Delhi.

Consent for publication

All the authors have scrutinized the script and give their consent for publication. 


\section{Competing interests}

The authors have no competing interests in any form.

\section{Author details}

${ }^{1}$ Department of Microbiology, ICMR-Regional Medical Research Centre (Department of Health Research, Ministry of Health \& Family Welfare, Government of India), Chandrasekharpur, Bhubaneswar 751023, India. ${ }^{2}$ Office of the Chief District Medical Officer Koraput, Department of Health and Family Welfare, Government of Odisha, Koraput 764020, India.

Received: 22 September 2021 Accepted: 5 January 2022

Published online: 15 January 2022

\section{References}

1. Fukao T. Immune system paralysis by anthrax lethal toxin: the roles of innate and adaptive immunity. Lancet Infect Dis. 2004;4:166-70.

2. Tuchili LM, Pandey GS, Sinyangwe PG, Kaji T. Anthrax in cattle, wildlife and humans in Zambia. Vet Rec. 1993:132:487.

3. Walsh MG, de Smalen AW, Mor SM. Climatic influence on anthrax suitability in warming northern latitudes. Sci Rep. 2018;8:9269.

4. Dey R, Hoffman PS, Glomski IJ. Germination and amplification of anthrax spores by soil-dwelling amoebas. Appl Environ Microbiol. 2012;78:8075-81.

5. OIE listed diseases and other diseases of importance., OIE Terrestrial Manual; 2018. p. 307-320. Available from: https://www.oie.int/fileadmin/ Home/eng/Health_standards/tahm/3.01.01_ANTHRAX.pdf.

6. Goossens PL. Animal models of human anthrax: the Quest for the Holy Grail. Mol Aspects Med. 2009;30:467-80.

7. Dixon TC, Meselson M, Guillemin J, Hanna PC. Anthrax. N Engl J Med. 1999;341:815-26

8. D'Amelio E, Gentile B, Lista F, D'Amelio R. Historical evolution of human anthrax from occupational disease to potentially global threat as bioweapon. Environ Int. 2005:85:133-46.

9. Sitali DC, Mumba C, Skjerve E, Mweemba O, Kabonesa C, Mwinyi MO, et al. Awareness and attitudes towards anthrax and meat consumption practices among affected communities in Zambia: a mixed methods approach. PLoS Negl Trop Dis. 2017;11:e0005580.

10. Patil RR. Anthrax: public health risk in India and socio-environmental determinants, Indian. J Community Med. 2010;35:189-90.

11. Bhattacharya D, Barla D, Pati S. How can anthrax outbreaks be prevented in Odisha? 2019) Available from: https://main.icmr.nic.in/content/policybrief. Accessed 26 Feb 2021.

12. Sahoo KC, Negi S, Barla D, Badaik G, Sahoo S, Bal M, et al. The landscape of anthrax prevention and control: stakeholders' perceptive in Odisha, India. Int J Environ Res Public Health. 2020;17:3094.

13. Bhattacharya D, Kshatri JS, Choudhary HR, Parai D, Shandilya J, Mansingh A, et al. One Health approach for elimination of human anthrax in a tribal district of Odisha: study protocol. PLOS ONE. 2021:16:e0251041.

14. Makurumidze R, Gombe NT, Magure T, Tshimanga M. Investigation of an anthrax outbreak in Makoni District, Zimbabwe. BMC Public Health 2021:21:298.

15. Dragon DC, Rennie RP. The ecology of anthrax spores: tough but not invincible. Can Vet J. 1995;36:295-301.

16. Chakraborty A, Khan SU, Hasnat MA, Parveen S, Islam MS, Mikolon A, et al. Anthrax outbreaks in Bangladesh, 2009-2010. Am J Trop Med Hyg. 2012;86:703-10

17. Kracalik I, Malania L, Broladze M, Navdarashvili A, Imnadze P, Ryan SJ, et al. Changing livestock vaccination policy alters the epidemiology of human anthrax, Georgia, 2000-2013. Vaccine. 2017;35:6283-9.

18. Hampson K, Lembo T, Bessell P, Auty H, Packer C, Halliday J, et al. Predictability of anthrax infection in the Serengeti, Tanzania. J Appl Ecol. 2011:48(6):1333-44.

19. Turner WC, Imologhome P, Havarua Z, Kaaya GP, Mfune JKE, Mpofu IDT, et al. Soil ingestion, nutrition and the seasonality of anthrax in herbivores of Etosha National Park. Ecosphere. 2013;4(1):art13.

20. Munang'andu HM, Banda F, Siamudaala VM, Munyeme M, Kasanga CJ, Hamududu B. The effect of seasonal variation on anthrax epidemiology in the upper Zambezi floodplain of western Zambia. J Vet Sci. 2012;13(3):293-8.
21. Kracalik I, Malania L, Broladze M, Navdarashvili A, Imnadze P, Ryan SJ, et al. Changing livestock vaccination policy alters the epidemiology of human anthrax, Georgia, 2000-2013. Vaccine. 2017;35(46):6283-9.

22. Maudlin I, Eisler MC, Welburn SC. Neglected and endemic zoonoses. Philos Trans R Soc Lond B. 2009;364:2777-87.

\section{Publisher's Note}

Springer Nature remains neutral with regard to jurisdictional claims in published maps and institutional affiliations.
Ready to submit your research? Choose BMC and benefit from:

- fast, convenient online submission

- thorough peer review by experienced researchers in your field

- rapid publication on acceptance

- support for research data, including large and complex data types

- gold Open Access which fosters wider collaboration and increased citations

- maximum visibility for your research: over 100M website views per year

At BMC, research is always in progress.

Learn more biomedcentral.com/submissions 